\title{
Standards of aminoglycoside therapeutic drug monitoring in a South African private hospital: perspectives and implications
}

\author{
Mariette du Toit ${ }^{1}$, Johanita R. Burger ${ }^{1}$, Dorcas M. Rakumakoe ${ }^{1}$ and Malie Rheeders ${ }^{2}$ \\ Ghana Med J 2019; 53(1): 8-12 http://dx.doi.org/10.4314/gmj.v53i1.2
}

\author{
${ }^{1}$ Medicine Usage in South Africa (MUSA), Faculty of Health Sciences, North-West University, Potchefstroom, \\ South Africa \\ ${ }^{2}$ Centre of Excellence for Pharmaceutical Science, North-West University, Potchefstroom, South Africa \\ Corresponding author: Malie Rheeders \\ E-mail: malie.rheeders@nwu.ac.za
}

Conflict of interest: None declared

\section{SUMMARY}

Background: Therapeutic drug monitoring (TDM) is essential to ensure that aminoglycoside peak concentrations are high enough for effective antimicrobial treatment and trough levels are low enough to minimise toxicity. Inappropriate utilisation of TDM may lead to suboptimal therapy, toxicity and waste of resources. This study aimed to investigate the standard of aminoglycoside TDM performed in adult hospitalised patients.

Design: An observational, descriptive, cross-sectional study.

Setting: A 221-bed private hospital.

Participants: All patients, older than 18 years, on intravenous aminoglycosides for more than 48 hours were included. Interventions: None, was observational. A computerised database and patient files were used to obtain the information required for this study. Descriptive statistical analysis was used.

Main outcomes measures: Aminoglycoside blood levels and estimated glomerular filtration rate (eGFR) in the patients.

Results: One hundred and three (103) patients were included: 65 on gentamicin and 38 on amikacin. Blood levels were performed in only 19 gentamicin $(29.23 \%)$ and 22 amikacin (57.89\%) patients. Trough levels were taken more than 2 hours before the next dose in 12 gentamicin $(63.16 \%)$ and 12 amikacin $(54.54 \%)$ patients. The majority of patients $(96.92 \%$ on gentamicin and $84.21 \%$ on amikacin) received once daily doses. TDM was performed in all patients with an estimated glomerular filtration rate (eGFR) lower than $60 \mathrm{~mL} / \mathrm{min} / 1.73 \mathrm{~m}^{2}$ and in $23.31 \%$ of gentamicin patients and $56.76 \%$ of amikacin patients with an eGFR higher than $60 \mathrm{mg} / \mathrm{min} / 1.73 \mathrm{~m}^{2}$.

Conclusions: Incorrect sampling times and unnecessary levels taken in patients with normal renal function indicate a need for aminoglycoside treatment guidelines in the private hospital.

Funding: None

Keywords: Aminoglycosides, Dosing considerations, South Africa, Therapeutic Drug Monitoring, Sampling times

\section{INTRODUCTION}

Therapeutic drug monitoring (TDM) is defined as the measured drug concentration combined with adequate medical interpretation to influence the drug therapy in patients ${ }^{1}$ and an important tool in pharmacotherapy. The purpose of TDM is to individualise the therapeutic regimen of the patient to gain optimal benefit with the lowest toxicity. Research has shown blood samples for TDM purposes are not always taken correctly and protocols do not exist, or are not always followed, ${ }^{2}$ which can lead to incorrect dosing regimens and waste of time and resources, especially in developing countries. ${ }^{2}$

Measurement of aminoglycoside concentrations and dosage individualisation should be standard practice for all critically ill patients treated with aminoglycosides. ${ }^{3}$
Aminoglycoside antibiotics are concentration-dependent - a higher antibiotic concentration $\left(\mathrm{C}_{\max }\right)$ to minimum inhibitory concentration $(\mathrm{MIC})$ ratio $\left(\mathrm{C}_{\max }: \mathrm{MIC}\right)$ will exhibit a greater antimicrobial activity. Aminoglycosides also exhibit a post-antibiotic effect, meaning that a persistent suppression of bacterial growth is demonstrated even after drug concentration drops below the MIC. ${ }^{4}$

The hydrophilic nature of aminoglycosides can lead to changes in volume of distribution in certain conditions, such as sepsis, which can lower peak concentrations and the effect of the drug. ${ }^{3}$ Aminoglycosides are mainly 
excreted in the kidneys and many critically ill patients present with impaired renal function. In patients with impaired renal function, two samples (peak and trough) are recommended to individualise the regimen by using the Sawchuk-Zaske calculations or Bayesian approaches. $^{5}$

Guidelines to perform TDM become even more important in Intensive Care Units (ICUs) where the weights of the patients may be unknown and their pharmacokinetics can change daily. The once daily dosing regimen adopted over the past few years is based on the assumption that the peak concentration will be adequate for most infections and peak levels are not routinely requested. There is, however, evidence indicating that the length of hospital stay is decreased and nephrotoxicity reduced by aminoglycoside dosage individualisation in critically ill patients, ${ }^{1,3}$ therapeutic drug monitoring, therefore also improves overall patient outcome.

The South African Medicines Formulary (SAMF) recommends that trough levels be obtained 48 to 72 hours after commencement of therapy, immediately prior to the next dose, and dose or interval adjustments made if necessary. It also recommends a peak level for effective bacterial kill after the second dose. There is limited data on TDM of aminoglycosides in South Africa, therefore this study was performed to evaluate the standard of this service in a private hospital.

\section{METHODS}

\section{Study design and population}

The study was an observational, descriptive, retrospective, cross-sectional study conducted in a 221bed private hospital located in the Western Cape, South Africa. The target population included all patients who received gentamicin and amikacin, for longer than 48 hours, during the research period. The study population consisted of all patients, 18 years and older, who received aminoglycosides whilst admitted in the hospital during the research period from November 2014 to October 2016. Patients from the emergency centre, or who received aminoglycosides as surgical prophylaxis were excluded from the study.

The measurements taken were to determine the dosages of aminoglycosides prescribed, the percentage of patients where drug levels were monitored, the percentage of patients with abnormal renal function where TDM was done and whether dosages were adjusted in case of drug levels outside of the normal range.

\section{Data collection}

Patient files and a computerised database were used to collect data at a specific time point. The hospital dispensing programme was used to find patient numbers for patients who received gentamicin or amikacin treatment. Data collected from the patient's files included the patient's age, gender and weight, the dosage of aminoglycoside prescribed and frequency, as well as time of day when gentamicin or amikacin were prescribed.

Laboratory reports were used to determine the peak and trough levels in cases where blood samples were taken for TDM. The laboratory results were also used to determine whether the results were within normal reference ranges. The following was documented: dosages prescribed, patient weight, age and gender, time of collection of blood sample, whether the drug levels were within reference ranges and patient renal function.

\section{Data analysis}

The statistical analysis was performed using the SPSS programme. ${ }^{6}$ Descriptive statistical analysis was used to describe and summarise data. Categorical variables were expressed as frequencies and percentages, and continuous variables were expressed as mean and standard deviations (SDs).

\section{Ethical considerations}

Permission to conduct the study was obtained from the Health Research Ethics Committee of North-West University (NWU-00363-15-A1). Goodwill permission was obtained from the hospital group's corporate office, the hospital manager and manager of the laboratory.

\section{RESULTS}

This study comprised 178 files of patients who received aminoglycosides while admitted to the private hospital during the study period of 1 November 2014 and 31 October 2016. Of these, 103 patient files met the inclusion criteria. The 75 patients excluded from the study either received aminoglycosides as surgical prophylaxis, or were treated for less than 48 hours. Sixtyfive patients received gentamicin and 38 amikacin.

\section{Demographic characteristics of the patients}

The demographic characteristics of the patients are shown in Table I. Of the 65 patients on gentamicin (mean age $57.38 \pm 15.16$ years $), 63.10 \%(n=41)$ were males. Patients on amikacin were marginally younger at 54.29 \pm 22.85 years (Cohen's $d=0.14$ ) and of these, $60.53 \%$ $(n=23)$ were males.

Only two patients on gentamicin had an estimated glomerular filtration rate (eGFR) of lower than 60 $\mathrm{mL} / \mathrm{min} / 1.73 \mathrm{~m}^{2}$, compared to one patient on amikacin. Most of the patients, $66.10 \%$ in the gentamicin and 
$55.26 \%$ in the amikacin group, had eGFR values higher than $90 \mathrm{mg} / \mathrm{min} / 1.73 \mathrm{~m}^{2}$.

Table I Patient demographics

\begin{tabular}{|l|l|l|}
\hline & $\begin{array}{l}\text { Gentamicin } \\
(\mathrm{N}=65)\end{array}$ & $\begin{array}{l}\text { Amikacin } \\
(\mathrm{N}=38)\end{array}$ \\
\hline Age (years), mean \pm SD & $57.38 \pm 15.16$ & $54.29 \pm 22.85$ \\
\hline Gender, $\mathbf{n}(\%)$ & & \\
\hline Male & $41(63.10)$ & $23(60.53)$ \\
\hline Female & $24(36.90)$ & $15(39.47)$ \\
\hline \multicolumn{2}{|l}{} \\
\hline$<60 \mathrm{~mL} / \mathrm{min} / 1.73 \mathrm{~m}^{2}$ & $2(3.08)$ & $1(2.63)$ \\
\hline $60-90 \mathrm{~mL} / \mathrm{min} / 1.73 \mathrm{~m}^{2}$ & $15(23.08)$ & $15(39.48)$ \\
\hline$>90 \mathrm{~mL} / \mathrm{min} / 1.73 \mathrm{~m}^{2}$ & $43(66.15)$ & $21(55.26)$ \\
\hline Renal function not tested & $5(7.69)$ & $1(2.63)$ \\
\hline
\end{tabular}

Table 2 Dosage and blood level results for the patients

\begin{tabular}{|c|c|c|}
\hline & $\begin{array}{l}\text { Gentamicin } \\
\mathbf{n}(\%)\end{array}$ & $\begin{array}{l}\text { Amikacin } \\
\mathbf{n}(\%)\end{array}$ \\
\hline \multicolumn{3}{|l|}{ Dosage } \\
\hline $240 \mathrm{mg} /$ day & $38(58.5)$ & $\mathrm{n} / \mathrm{a}$ \\
\hline $160 \mathrm{mg} /$ day & $10(15.4$ & $\mathrm{n} / \mathrm{a}$ \\
\hline $400 \mathrm{mg} / \mathrm{day}$ & $7(10.8)$ & $\mathrm{n} / \mathrm{a}$ \\
\hline $180 \mathrm{mg} /$ day & $5(7.7)$ & $\mathrm{n} / \mathrm{a}$ \\
\hline $320 \mathrm{mg} /$ day & $2(3.1)$ & $\mathrm{n} / \mathrm{a}$ \\
\hline $80 \mathrm{mg} 8$-hourly & $2(3.1)$ & $\mathrm{n} / \mathrm{a}$ \\
\hline $480 \mathrm{mg} /$ day & $4(1.5)$ & $\mathrm{n} / \mathrm{a}$ \\
\hline $1000 \mathrm{mg} / \mathrm{day}$ & $\mathrm{n} / \mathrm{a}$ & $30(78.95)$ \\
\hline $500 \mathrm{mg} 12$-hourly & $\mathrm{n} / \mathrm{a}$ & $5(13.16)$ \\
\hline $750 \mathrm{mg} / \mathrm{day}$ & $\mathrm{n} / \mathrm{a}$ & $2(5.26)$ \\
\hline $1000 \mathrm{mg} 12$-hourly & $\mathrm{n} / \mathrm{a}$ & $1(2.63)$ \\
\hline \multicolumn{3}{|l|}{ TDM results } \\
\hline$<1 \mathrm{mg} / \mathrm{L}$ & $13(20.00)$ & $\mathrm{n} / \mathrm{a}$ \\
\hline$>1 \mathrm{mg} / \mathrm{L}$ & $6(9.23)$ & $\mathrm{n} / \mathrm{a}$ \\
\hline$<5 \mathrm{mg} / \mathrm{L}$ & $\mathrm{n} / \mathrm{a}$ & $19(50.00)$ \\
\hline$>5 \mathrm{mg} / \mathrm{L}$ & $\mathrm{n} / \mathrm{a}$ & $3(7.89)$ \\
\hline No TDM done & $46(70.77)$ & $16(42.11)$ \\
\hline \multicolumn{3}{|c|}{ TDM for eGFR $<60 \mathrm{~mL} / \mathrm{min} / 1.73 \mathrm{~m}^{2}$} \\
\hline TDM done & $2(100)$ & $1(100)$ \\
\hline TDM not done & 0 & 1 \\
\hline \multicolumn{3}{|c|}{ TDM for eGFR $>60 \mathrm{~mL} / \mathrm{min} / 1.73 \mathrm{~m}^{2}$} \\
\hline TDM done & $17(29.31)$ & $21(56.76)$ \\
\hline TDM not done & $41(70.69)$ & $16(43.24)$ \\
\hline \multicolumn{3}{|c|}{ TDM done where eGFR not tested } \\
\hline TDM done & 0 & 0 \\
\hline TDM not done & $5(100)$ & 0 \\
\hline \multicolumn{3}{|l|}{ Sampling times } \\
\hline $0-1$ hour before next dose & $1(5.26)$ & $5(22.73)$ \\
\hline 1-2 hours before next dose & $6(31.58)$ & $5(22.73)$ \\
\hline$>2$ hours before next dose & $12(63.16)$ & $12(54.54)$ \\
\hline
\end{tabular}

\section{Dosages and blood level results of the patients}

Table 2 shows the dosages and blood level results according to ideal trough level concentrations and renal functions, and sampling times for patients on gentamicin and amikacin, respectively.

The sampling time refers to the time when blood was drawn to measure aminoglycoside levels. In all patients, levels taken were trough levels.
Only two patients $(3.08 \%)$ on gentamicin received an eight-hourly dose, 63 patients received a once daily dose and $38(60.32 \%)$ received a dose of $240 \mathrm{mg}$ daily, see table 3. Blood levels were drawn in only $19(29.23 \%)$ of the patients and 13 levels were lower than $1 \mathrm{mg} / \mathrm{L}$ and six levels higher than $1 \mathrm{mg} / \mathrm{L}$. Therapeutic drug monitoring was performed in both patients with a renal function of lower than $60 \mathrm{~mL} / \mathrm{min} / 1.73 \mathrm{~m}^{2}$. The renal function was higher than $60 \mathrm{~mL} / \mathrm{min} / 1.73 \mathrm{~m}^{2}$ in $17(89.47 \%$ ) patients on gentamicin where TDM was performed.

Table 3 Dosage and blood level results for the patients

\begin{tabular}{|c|c|c|}
\hline & $\begin{array}{l}\text { Gentamicin } \\
\mathbf{N}(\%)\end{array}$ & $\begin{array}{l}\text { Amikacin } \\
\mathbf{N}(\%)\end{array}$ \\
\hline \multicolumn{3}{|l|}{ Dosage } \\
\hline $240 \mathrm{mg} /$ day & $38(58.5)$ & $\mathrm{n} / \mathrm{a}$ \\
\hline $160 \mathrm{mg} / \mathrm{day}$ & $10(15.4$ & $\mathrm{n} / \mathrm{a}$ \\
\hline $400 \mathrm{mg} / \mathrm{day}$ & $7(10.8)$ & $\mathrm{n} / \mathrm{a}$ \\
\hline $180 \mathrm{mg} /$ day & $5(7.7)$ & $\mathrm{n} / \mathrm{a}$ \\
\hline $320 \mathrm{mg} /$ day & $2(3.1)$ & $\mathrm{n} / \mathrm{a}$ \\
\hline $80 \mathrm{mg} 8$-hourly & $2(3.1)$ & $\mathrm{n} / \mathrm{a}$ \\
\hline $480 \mathrm{mg} /$ day & $4(1.5)$ & $\mathrm{n} / \mathrm{a}$ \\
\hline $1000 \mathrm{mg} /$ day & $\mathrm{n} / \mathrm{a}$ & $30(78.95)$ \\
\hline 500 mg 12-hourly & $\mathrm{n} / \mathrm{a}$ & $5(13.16)$ \\
\hline $750 \mathrm{mg} / \mathrm{day}$ & $\mathrm{n} / \mathrm{a}$ & $2(5.26)$ \\
\hline 1000 mg 12-hourly & $\mathrm{n} / \mathrm{a}$ & $1(2.63)$ \\
\hline \multicolumn{3}{|l|}{ TDM results } \\
\hline$<1 \mathrm{mg} / \mathrm{L}$ & $13(20.00)$ & $\mathrm{n} / \mathrm{a}$ \\
\hline$>1 \mathrm{mg} / \mathrm{L}$ & $6(9.23)$ & $\mathrm{n} / \mathrm{a}$ \\
\hline$<5 \mathrm{mg} / \mathrm{L}$ & $\mathrm{n} / \mathrm{a}$ & $19(50.00)$ \\
\hline$>5 \mathrm{mg} / \mathrm{L}$ & $\mathrm{n} / \mathrm{a}$ & $3(7.89)$ \\
\hline No TDM done & $46(70.77)$ & $16(42.11)$ \\
\hline \multicolumn{3}{|c|}{ TDM for $\mathrm{eGFR}<60 \mathrm{~mL} / \mathrm{min} / 1.73 \mathrm{~m}^{2}$} \\
\hline TDM done & $2(100)$ & $1(100)$ \\
\hline TDM not done & 0 & 1 \\
\hline \multicolumn{3}{|c|}{ TDM for eGFR $>60 \mathrm{~mL} / \mathrm{min} / 1.73 \mathrm{~m}^{2}$} \\
\hline TDM done & $17(29.31)$ & $21(56.76)$ \\
\hline TDM not done & $41(70.69)$ & $16(43.24)$ \\
\hline \multicolumn{3}{|c|}{ TDM done where eGFR not tested } \\
\hline TDM done & 0 & 0 \\
\hline TDM not done & $5(100)$ & 0 \\
\hline \multicolumn{3}{|l|}{ Sampling times } \\
\hline 0-1 hour before next dose & $1(5.26)$ & $5(22.73)$ \\
\hline 1-2 hours before next dose & $6(31.58)$ & $5(22.73)$ \\
\hline$>2$ hours before next dose & $12(63.16)$ & $12(54.54)$ \\
\hline
\end{tabular}

In the amikacin group, six patients $(\mathrm{N}=38)$ received a 12-hourly dose and $30(78.95 \%)$ patients received a dose of $1000 \mathrm{mg}$ daily. Blood levels were drawn in 22 $(57.89 \%)$ of the patients and 19 levels were lower than 5 $\mathrm{mg} / \mathrm{L}$ and three were higher than $5 \mathrm{mg} / \mathrm{L}$. Therapeutic drug monitoring was performed for the one patient on amikacin with a renal function lower than 60 $\mathrm{mL} / \mathrm{min} / 1.73 \mathrm{~m}^{2}$.

\section{DISCUSSION}

To our knowledge, this was the first study where the standard of therapeutic drug monitoring of aminoglycosides, gentamicin and amikacin were 
investigated in a private hospital in the Western Cape, South Africa, and resulted in a number of key findings. Firstly, in this study the male to female ratio was the same for gentamicin and amikacin groups, with approximately $60 \%$ males and $40 \%$ females.

It is important to remember that this is a general hospital and the study only investigated the patients on aminoglycosides, therefore it is not a reflection of all the patients admitted to the hospital. Kushner et al., 2016, ${ }^{7}$ reported a higher percentage of women on gentamicin in patients younger than 50 years.

Interestingly, in the population older than 55 years, the same age as the patients in this study, the usage of gentamicin was comparable with the results of this study. Secondly, we found that approximately $97 \%$ of patients in the gentamicin group and $84 \%$ in the amikacin group received once-daily doses of the drug, which is in line with literature recommendations for treatment ${ }^{8}$, as well as the South African guidelines for the use of aminoglycosides. ${ }^{9}$ In a survey performed in 2015 by Tabah et al., $94 \%$ of patients received once-daily doses of gentamicin and amikacin. ${ }^{10}$

Once daily dosing of aminoglycosides is associated with similar efficacy, but with fewer adverse effects due to the concentration dependent nature of the drug. ${ }^{11}$ Thirdly, we determined that trough levels only were performed for $29.23 \%$ of patients on gentamicin and $57.89 \%$ on amikacin treatment. The higher percentage of trough level measurements with amikacin compared to gentamicin needs further exploration. Although nephrotoxicity is an adverse effect with all aminoglycosides, literature indicates that gentamicin concentrate in the kidneys to a higher degree than the other aminoglycosides and therefore more prone to toxicity than amikacin. ${ }^{12}$

Trough levels are sufficient to determine the likelihood of adverse effects, but to calculate individual doses per patient to optimise treatment, it is necessary to measure both trough and peak levels. With these calculations, it can be ensured the desired MIC for the organism is reached, and trough levels are below threshold levels to prevent adverse effects. ${ }^{13}$ Peak levels become very important in critically ill patients with abnormal pharmacokinetics and in organisms with higher MIC levels.

When individualised patient dosages are calculated by measuring peak and trough levels, a greater percentage of patients will achieve the targeted concentration compared to those who receive fixed doses. Improved clinical outcomes are achieved in patients who attained targeted therapeutic serum concentrations early in treatment. ${ }^{4}$ To ensure optimal treatment of organisms, it is suggested that a $\mathrm{C}_{\max } / \mathrm{MIC}$ ratio of 8 to 10 is achieved. Whether this is the case in individual patients can only be determined if a peak level is measured. ${ }^{3}$

In patients with abnormal renal function (renal insufficiency) it is of utmost importance to take two levels to determine true peak and trough levels and individualise treatment for each patient; this has not been necessary in our study. This could lead to treatment failure in infections caused by organisms with higher MIC, because the peak level is not measured and not known to be 8 to 10 times the MIC. In critically ill patients, a peak and trough level can be used to individualise dosages and ensure optimal treatment. ${ }^{3}$

Fourthly, sampling time was not consistently within one hour before administration of the next dose. Of the six patients $(9.23 \%)$ in the gentamicin group, where the gentamicin levels were $>1 \mathrm{mg} / \mathrm{L}$, none of the samples was taken within one hour before administration of the next dose. In the amikacin group, there were three cases where the amikacin levels were $>5 \mathrm{mg} / \mathrm{L}$, and none of these was taken within one hour before administration of the next dose; of these values, none are therefore reliable and true trough levels.

Trough levels should be measured within one hour before the next dose and the peak levels 30 minutes after completing the intravenous injection. ${ }^{14}$ Incorrect sampling time will lead to incorrect trough levels, as actual levels just before administration of the next dose will be lower than the levels measured more than two hours earlier. A trough level, without the knowledge of the time sampled, can be mistaken for toxicity.

The South African Department of Health's guidelines suggest that trough levels for amikacin and gentamicin be measured three times per week in haemodynamically stable patients. ${ }^{9}$ In our study, TDM was performed in all patients with eGFR $<60 \mathrm{~mL} / \mathrm{min} / 1.73 \mathrm{~m}^{2}$, but in patients with eGFR> $60 \mathrm{~mL} / \mathrm{min} / 1.73 \mathrm{~m}^{2}$ it seems that TDM were done randomly and no pattern of practice could be found. In the gentamicin group, TDM was performed for $29.13 \%$ of patients with eGFR $>60 \mathrm{~mL} / \mathrm{min} / 1.73 \mathrm{~m}^{2}$ and in the amikacin group, TDM was performed for $56.67 \%$.

In the gentamicin group, there were five patients where eGFR was not tested at all and no TDM was done either. Similar results were found in a study by Al Za'abi et al., at a teaching hospital in Oman. ${ }^{2}$ The authors ascribed 
their results to incorrect sampling times and the lack of policy. ${ }^{2}$ Active TDM strategies (performed according to policy for all patients and not only when prescribed by the medical practitioner) result in reduced nephrotoxicity as well as a shorter hospital stay. ${ }^{3}$ Finally, we found that dosages were not calculated per patient according to weight. This might be because many of the patients were in ICU and could not be weighed.

\section{Limitations of this study}

This study reflects only the situation in a private hospital in South Africa and does not indicate the standard of TDM practices in other private or public hospitals in the country. As only retrospective data were used, the patient outcomes could not be determined. All information required to determine the standard of TDM in the private hospital was not available, as many patient's weights were not recorded in patient charts.

\section{CONCLUSION}

The study has shown that aminoglycoside levels are drawn, but the results are underutilised due to the lack of clear TDM guidelines. In this small population, most of the patients had normal renal function and most of the trough levels were within the recommended range, although levels were not always taken at the correct times and sample times were not always documented.

Hospital policy, in line with international TDM guidelines, can improve therapy and reduce the probability of toxicity, especially in patients with unstable or impaired renal function. The policy can also include peak levels in patients with resistant organisms and compromised pharmacokinetics to individualise therapy even further.

\section{ACKNOWLEDGEMENT}

The authors would like to thank the private hospital in the Western Cape, South Africa, for providing the data for this research project, and statistician Marike Cockeran, for data analysis.

\section{REFERENCES}

1. Kovačević T, Avram S, Milaković D, Špirić N, Kovačević P. Therapeutic drug monitoring of amikacin and gentamicin in critically and noncritically ill patients. J Basic Clin Pharm. 2016 Jun;7(3):65-9.

2. Al Za'abi M, Muqbali J, Al-Waili K. Sampling time and indications appropriateness for therapeutically monitored drugs at a teaching university hospital in Oman. Saudi Pharm J. 2015 Sep;23(4):458-62.

3. Roberts JA, Norris R, Paterson DL, Martin JH. Therapeutic drug monitoring of antimicrobials. $\mathrm{Br} \mathrm{J}$ Clin Pharmacol. 2012 Jan;73(1):27-36.

4. Avent ML, Rogers BA, Cheng AC, Paterson DL. Current use of aminoglycosides: indications, pharmacokinetics and monitoring for toxicity. Intern Med Journal. 2011 Jun;41(6):441-9.

5. Nezic L, Derungs A, Bruggisser M, Tschudin-Sutter S, Krähenbühl S, Haschke M. Therapeutic drug monitoring of once daily aminoglycoside dosing: comparison of two methods and investigation of the optimal blood sampling strategy. Eur J Clin Pharmacol. 2014 Jul;70:829-37.

6. IBM Corp. IBM SPSS Statistics for Windows. Version 24.0. Armonk,: IBM Corp; 2013.

7. Kushner B, Allen PD, Crane BT. Frequency and demographics of gentamicin use. Otol Neurotol. 2016 Feb;37(2):190-5.

8. Beaucaire, G. Does once-daily dosing prevent nephrotoxicity in all aminoglycosides equally? Clin Microbiol Infect. $2000 \mathrm{Jul} ; 6(7): 355-60$.

9. South Africa. Department of Health. Hospital level adults standard treatment guidelines and essential medicine list for South Africa. 4th ed. Pretoria: National Department of Health; 2015.

10. Tabah A, De Waele J, Lipman J, Zahar JR, Cotta MO, Barton G, et al. The ADMIN-ICU survey: a survey on antimicrobial dosing and monitoring in ICUs. J Antimicrob Chemother. 2015 Sep;70(9):2671-7.

11. Stankowicz MS, Ibrahim J, Brown DL. Once-daily aminoglycoside dosing: An update on current literature. Am J Health Syst Pharm. 2015 Aug;72(16):1357-64.

12. Sweileh WM. A prospective comparative study of gentamicin and amikacin induces nephrotoxicity in patients with normal baseline renal function. Fundam Clin Pharmacol. 2009 Aug; 23 (9):515-20.

13. Touw DJ, Westerman EM, Sprij AJ. Therapeutic drug monitoring of aminoglycosides in neonates. Clin Pharmacokinet. 2009; 48 (2):71-88. Erratum in: Clin Pharmacokinet. 2009; 48 (3):209-10.

14. Hanberger H, Edlund C, Furebring M, G Giske C, Melhus A, Nilsson LE, et al. Rational use of aminoglycosides - review and recommendations by the Swedish Reference Group for Antibiotics (SRGA). Scand J Infect Dis. 2013 Mar; 45(3):16175 .

Copyright (C) The Author(s). This is an Open Access article under the CC BY license 